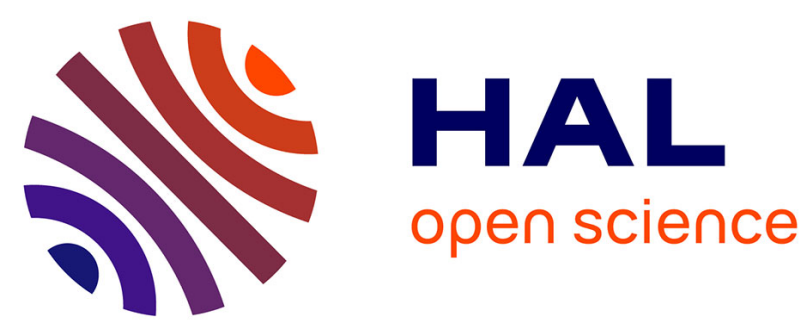

\title{
Evidence for biological effects of metformin in operable breast cancer: a pre-operative, window-of-opportunity, randomized trial
}

Sirwan Hadad, Takayuki Iwamoto, Lee Jordan, Colin Purdie, Susan Bray, Lee Baker, Gera Jellema, Steve Deharo, D. Grahame Hardie, Lajos Pusztai, et al.

\section{To cite this version:}

Sirwan Hadad, Takayuki Iwamoto, Lee Jordan, Colin Purdie, Susan Bray, et al.. Evidence for biological effects of metformin in operable breast cancer: a pre-operative, window-of-opportunity, randomized trial. Breast Cancer Research and Treatment, 2011, 128 (3), pp.783-794. 10.1007/s10549-011-1612-1. hal-00649460

\section{HAL Id: hal-00649460 \\ https://hal.science/hal-00649460}

Submitted on 8 Dec 2011

HAL is a multi-disciplinary open access archive for the deposit and dissemination of scientific research documents, whether they are published or not. The documents may come from teaching and research institutions in France or abroad, or from public or private research centers.
L'archive ouverte pluridisciplinaire HAL, est destinée au dépôt et à la diffusion de documents scientifiques de niveau recherche, publiés ou non, émanant des établissements d'enseignement et de recherche français ou étrangers, des laboratoires publics ou privés. 
Evidence for biological effects of metformin in operable breast cancer: a pre-operative, window of opportunity, randomized trial.

Sirwan Hadad $\mathrm{PhD}^{1}$, Takayuki Iwamoto, $\mathrm{MD}^{2}$, Lee Jordan MRCPath ${ }^{1}$, Colin Purdie $\mathrm{PhD}^{1}$, Susan Bray $\mathrm{PhD}^{1}$, Lee Baker $\mathrm{PhD}^{1}$, Gera Jellema MSc ${ }^{3}$, Steve Deharo $\mathrm{MSc}^{3}$, D Grahame Hardie $\mathrm{PhD}^{4}$, Lajos Pusztai DPhil ${ }^{2}$, Stacy Moulder-Thompson, MD ${ }^{2}$, John A Dewar FRCR ${ }^{1}$, Alastair M Thompson FRCSEd ${ }^{1,5}$.

${ }^{1}$ Dundee Cancer Center,

University of Dundee,

Ninewells Hospital and Medical School,

Dundee DD1 9SY, UK

${ }^{2}$ Department of Breast Medical Oncology

M.D. Anderson Cancer Center,

1400 Holcombe Boulevard,

Houston 77030

Texas USA

${ }^{3}$ Almac Diagnostics,

19 Seagoe Industrial Estate,

Craigavon BT63 5QD,

Northern Ireland

${ }^{4}$ College of Life Sciences,

University of Dundee,

Dow Street,

Dundee DD1 5EH, UK

${ }^{5}$ Department of Surgical Oncology

M.D. Anderson Cancer Center,

1515 Holcombe Boulevard,

Houston 77030

Texas USA 
Sirwan Hadad: s.hadad@nhs.net (trial chief investigator)

Takayuki Iwamoto: tiwamoto@mdanderson.org (bioinformatics)

Lee Jordan: lee.jordan@nhs.net, (lead pathologist)

Colin Purdie: colin.purdie@ nhs.net, (pathologist to cross check data)

Susan Bray: s.e.bray@dundee.ac.uk, (testing/development of immunohistochemistry)

Lee Baker: 1.baker@dundee.ac.uk, (trial statistician)

Gera Jellema: gera.jellema@almacgroup.com, (transciptome analyst)

Steve Deharo: steve.deharo@almacgroup.com, (transciptome analyst)

D Grahame Hardie: d.g.hardie@dundee.ac.uk, (metformin biochemist)

Lajos Pusztai: lpusztai@mdanderson.org, (bioinformatics advisor)

Stacy L Moulder-Thompson: smoulder@mdanderson.org, (trial design)

John A Dewar: johnadewar@ nhs.net, (lead oncologist)

Alastair M Thompson: a.m.thompson@dundee.ac.uk (guarantor)

All authors have contributed to writing the manuscript and have approved the final version.

\section{Correspondence to:}

Professor AM Thompson

Professor of Surgical Oncology

Dundee Cancer Centre

Ninewells Hospital and Medical School,

Dundee DD1 9SY

\section{a.m.thompson@dundee.ac.uk}

Tel: 00441382633936

Fax: 00441382496363 


\begin{abstract}
Metformin may reduce the incidence of breast cancer and enhance response to neoadjuvant chemotherapy in diabetic women. This trial examined the effects of metformin on Ki67 and gene expression in primary breast cancer.

Non-diabetic women with operable invasive breast cancer received pre-operative metformin. A pilot cohort of 8 patients had core biopsy of the cancer at presentation, a week later (without treatment; internal control), then following metformin 500mg o.d. for one week increased to $1 \mathrm{~g}$ b.d. for a further week continued to surgery. A further 47 patients had core biopsy at diagnosis, were randomized to metformin (the same dose regimen) or no drug, and 2 weeks later had core biopsy at surgery. Ki67 immunohistochemistry, transcriptome analysis on formalin fixed paraffin embedded cores and serum insulin determination were performed blinded to treatment.
\end{abstract}

7 patients $(7 / 32,21.9 \%)$ receiving metformin withdrew due to gastrointestinal upset. The mean percentage of cells staining for Ki67 fell significantly following metformin treatment in both the pilot cohort ( $\mathrm{p}=0.041$, paired $\mathrm{t}$-test) and in the metformin arm $(\mathrm{p}=0.027$, Wilcoxon rank test) but was unchanged in the internal control or metformin control arms. Messenger RNA expression was significantly down-regulated by metformin for PDE3B (phosphodiesterase 3B, cGMP-inhibited; a critical regulator of cAMP levels which affect activation of AMP-activated protein kinase, AMPK), confirmed by immunohistochemistry, SSR3, TP53 and CCDC14. By Ingenuity Pathway Analysis, the Tumour Necrosis Factor Receptor 1 (TNFR1) signaling pathway was most affected by metformin: TGFB, MEKK were up-regulated and cdc42 down-regulated; mTOR and AMPK pathways were also affected. Gene Set Analysis additionally revealed that p53, BRCA1 and cell cycle pathways also had reduced expressed following metformin. Mean serum insulin remained stable in patients receiving metformin but rose in control patients.

This trial presents biomarker evidence for anti-proliferative effects of metformin in women with breast cancer and provides support for therapeutic trials of metformin.

\title{
Key words
}

Breast cancer; metformin; ki67; transcriptome analyses; clinical trial. 


\section{Introduction}

Clinical observations have highlighted metformin as a potential anti-cancer therapy. Diabetics treated with metformin have a $23 \%$ reduced risk of cancer, including breast cancer, compared to those on sulfonylureas [1] and a lower cancer-related mortality at 36 months [2]. Coincidental use of metformin in diabetics undergoing neoadjuvant chemotherapy for breast cancer resulted in a higher pathological complete response (24\%), compared to diabetics not on metformin (8\%) or non-diabetic patients (16\%) [3].

Metformin activates AMP-activated protein kinase (AMPK)[4] by inhibiting mitochondrial ATP production and thus increasing cellular ADP:ATP and AMP:ATP ratios [5]. AMPK is involved in regulating energy balance at the cellular and whole body levels $[6,7]$ and is activated by stresses that deplete ATP, including glucose deprivation $[8,9]$ and hypoxia. Activation of the AMPK pathway by metformin in breast cancer cell lines reduces cellular proliferation, and is associated with reduced activation of mTOR and S6 kinase [10]. AMPK activation may be down-regulated in untreated primary breast cancer [11] suggesting reactivation of the AMPK pathway may inhibit tumours, sparing normal tissues which already have an active AMPK pathway. Treatment with metformin induces G0/G1 cell cycle arrest and inhibits cell proliferation independently of estrogen receptor (ER) and HER2 in pre-clinical models [12]. The anti-tumour effect of metformin may also be enhanced by an anti-hyperglycemic effect through suppression of hepatic gluconeogenesis, reducing the growth-promoting and mitogenic effects of circulating insulin [13].

The mechanisms of action of metformin in primary breast cancer merit further investigation [14] and are the subject of on going clinical trials [15]. Given the known mechanisms of action of metformin, it was hypothesized that treatment with metformin would reduce tumour proliferation as detected with immunohistochemistry using a preoperative "window of opportunity" trial design. The effects of metformin on breast cancer biomarkers in vivo, on serum insulin and clinical side effects in women with primary, previously untreated breast cancer were also examined. 


\section{Methods}

\section{Patients}

Between July 2007 and August 2009, 55 women with newly diagnosed stage I or II primary breast cancer, $>1 \mathrm{~cm}$ in size, bone marrow function within normal limits, liver and renal function tests within 1.5 times normal and with a life expectancy of at least 6 months were recruited (Figure 1). Trial patients had no history of diabetes (and no evidence of diabetes on blood biochemistry), no concomitant anti-cancer treatment or investigational drug within one month of study participation. Tayside Local Research Ethics Committee (07/S1402/19), Medicines and Healthcare products Regulatory Agency (MHRA) approval and written informed consent from all participants were obtained.

\section{Randomization and masking}

The study comprised two cohorts (Figure 1). The initial 8 patients were evaluated as a pre-planned, non-randomized, feasibility cohort A within the study. The remaining 47 patients were randomized 1:1 in an unblinded treatment vs. non-treatment trial design. Patients in both cohorts were treated with the same dosing schedule of oral metformin: $500 \mathrm{mg}$ daily for one week, increased to $1 \mathrm{~g}$ twice daily until surgery 1 further week later. Patients and clinical trial staff were not blinded to metformin use. All tumor samples analyzed were obtained by 14 gauge core needle biopsy at the given time points described below. At the time of surgical resection, core biopsies were obtained after the induction of general anesthesia, just prior to tumour resection. All specimens were processed identically in the same laboratory by researchers blinded to the treatment assignment. Samples were anonymized by trial number and remained blinded until laboratory and statistical analyses were complete. Core biopsies were formalin-fixed for 12 hours at room temperature, processed in a single pathology laboratory and paraffin embedded (formalin-fixed paraffin-embedded, FFPE) before molecular analysis and immunohistochemistry.

Patients treated in the pilot Cohort $\mathrm{A}(\mathrm{n}=8)$ had tumor core biopsies at three time points: diagnostic cores at clinical presentation; one week later (internal control sample) and following oral metformin. The third core biopsy was taken at the time of surgical resection, 2 weeks after starting metformin.

Cohort B patients $(n=47)$ were randomized using a randomization table (www.Randomization.com) to receive metformin or no medication. Core biopsies were taken at two time points: diagnosis and at the time of surgery 2 weeks later. The feasibility cohort suggested a power to reject the null hypothesis that the population means of the metformin and control groups were equal with a power of $80 \%$ and a type 1 error probability of 0.05 .

\section{Immunohistochemistry}

Immunohistochemical was performed on $4 \mu \mathrm{m}$ sections of FFPE tissues using standard methodologies. The primary antibodies comprised NCL-L-Ki67-MM1 (Anti-Ki67, 
monoclonal antibody, Leica Microsystems), sc-20793 (anti PDE3B (H-330), polyclonal, Santa Cruz Biotechnology), DO1 (anti-p53 monoclonal antibody [16]), estrogen receptor alpha (ER) antibody 6F11 (1:200; Novocastra Laboratories Ltd), progesterone receptor (PR) antibody clone 16 (1:800; Novocastra Laboratories Ltd) and anti-HER2 antibody (CB11; Novocastra Laboratories Ltd). Negative controls (lacking primary antibody) were performed for all staining runs.

Immunohistochemistry was conducted blinded to the clinical data and scored by a single specialist breast pathologist (LJ). Following light microscopy review, slides were scanned into a virtual microscopy format using an Aperio ScanScope XT TM (Aperio Technologies, Vista, Ca., USA) at the $\mathrm{x} 40$ objective utilizing standard compression methodology.

The Ki67 index (percentage of nuclear positive cells) per invasive tumor was calculated using manual annotation of the virtual microscopy slide by means of a Wacom Bamboo Pen \& Touch tablet device (Wacom Corporation, Saitama Japan) within the WebScope environment (version 10.2.0.2319) of the Aperio Spectrum Plus system version 10.2.2.2317. The annotations were assessed by the Aperio IHC nuclear Algorithm version 10. Only invasive tumor cells were assessed; great care was taken to exclude normal epithelial, in situ epithelial, stromal and inflammatory elements. A mean 5600 nuclei (range 601-39,788) per invasive tumor was assessed to obtain the Ki67 index. A minimum 1000 invasive tumor cells were examined except for one pretreatment and one post-treatment core (601 and 825 cells respectively).

PDE3B (cytoplasmic) and D01 (nuclear) staining were scored utilizing the "QuickScore" method (intensity and proportion of invasive tumor cells stained) [17]. SSR3 and GINS2 immunohistochemistry was unsuccessful despite extensive work with commercially available antibodies. ER and PR scoring used the Allred method in line with UK National Health Service (NHS) Breast Screening Program reporting recommendations [18]. HER2 scoring was assessed as previously described [19].

\section{Insulin measurements}

For cohort B patients, non-fasting venous blood was withdrawn, as per protocol, for insulin level determinations at diagnostic biopsy and at surgery following induction of anesthesia. At diagnostic biopsy, performed at the diagnostic breast clinic, the patients had not been fasted; at surgery, all patients had been fasted for 8 hours and were receiving intravenous fluids, including $5 \%$ glucose. Insulin was measured by the Siemens Immulite 2000 insulin assay in an accredited NHS clinical biochemistry laboratory and pair-wise comparison performed using a two sample t-test.

\section{Statistical analyses}

For Ki67 analysis, the mean change in Ki67 was calculated between each time point; the Anderson-Darling test was used to test for normal distribution and parametric (paired ttest) or non-parametric (Wilcoxon matched pairs signed rank test) statistics applied. Insulin levels in cohort B patients were compared at diagnosis with insulin levels following metformin or after no medication using a two sample t-test. A probability of $<5 \%$ was considered significant. 


\section{RNA Microarray}

For RNA microarray analysis, samples from all cohort A patients $(n=8)$, cohort B treatment group patients who continued metformin to surgery $(n=14)$, and $4 / 22$ randomly selected patients from the cohort B control group were successfully analyzed (Figure 2). RNA from the remaining cohort B control samples were not examined due to cost constraints. Tumor confirmation on a Haematoxylin and Eosin slide was confirmed by LJ. RNA extraction and Breast Cancer Disease-Specific Array (DSA) gene expression profiling were performed by ALMAC Diagnostics Group (Craigavon, UK).

RNA was isolated from FFPE tissue section "curls" in RNase-free tubes, the quality of the RNA samples and single stranded cDNA evaluated by spectrophotometric and bioanalyzer methodologies (Agilent Technologies UK Limited, Stockport, UK). One sample from a cohort A patient failed to meet the minimum RNA concentration, so all samples from this patient were excluded. Arrays were washed, stained and scanned in accordance with the Affymetrix GeneChip ${ }^{\circledR}$ Expression Analysis technical manual (Affymetrix UK Ltd., Buckinghamshire, UK).

\section{Data analysis}

Two samples were excluded following initial profile quality assessment based on standard Affymetrix array quality metrics and sample intensity distributions.

\section{Basic Analysis}

The data was corrected for background noise, summarized and normalized using RMA in Partek ${ }^{\circledR}$ Genomics Suite ${ }^{\mathrm{TM}}$ software, 6.5 beta $@ 2009$ (Partek Inc., St. Louis, MO, USA). Principle component analysis (PCA) revealed that the main variance associated with the first principle component was array quality. An additional transformation based in singular value decomposition was performed to remove this technical variation. The data was subsequently $\log 2$ transformed.

\section{Differential Gene Selection:}

Reliably detected genes were selected by removing the probe sets with a variance below the mean global variance. The genes were then filtered based on fold change $(>1.3$ for less stringent and 1.5 for stringent selection) to select the differentially expressed probe sets between the experimental group (after metformin) and the baseline group (before metformin). A student's t-test without multiple testing correction was performed and significant genes ( $p$-value $<0.05$ for less stringent and $p$-value $<0.005$ for stringent selection) selected for further analysis.

\section{Ingenuity Pathway Analysis (IPA)}

Ingenuity Pathway Analysis (IPA) analysis mapped genes differentially expressed between baseline and follow-up biopsies to biological pathways using the standard commercial software (IPA, http://www.ingenuity.com)

\section{Gene Set Analysis (GSA)}

Gene Set Analysis (GSA) examined whether members of a particular biological pathway occur toward the top or the bottom of a rank-ordered gene list including all gene expression measurements ranked by differential expression between baseline and metformin treatment. This analysis takes into account information from members of a pathway that would not make it to the top most differentially expressed gene list (used for 
the IPA analysis above). GSA was performed using the BRB Array Tools software package (http://linus.nci.nih.gov/BRB-ArrayTools.html , US NCI Biometrics Branch) for 2,987 gene sets collectively representing most known biological and metabolic pathways in Gene Ontology (GO, http://www.geneontology.org). To be included, a GO gene set required a minimum of 10 and a maximum of 200 genes. Significance was estimated with a permutation test $(n=1000)$. The null hypothesis was that the average degree of differential expression of members of a given gene set between the baseline and second biopsy was the same as expected from a random permutation of biopsy labels. IPA software was used to generate pathway figures for the significant gene sets. 


\section{Results}

\section{Clinical effects of metformin}

Fifty-five non-diabetic women consented to the trial (Figure 1). Despite the careful design of a feasibility cohort and then a randomized trial, there was withdrawal of patients due to gastrointestinal toxicity and loss of samples during tissue acquisition or processing. Thus the numbers in some groups are less than originally designed and the conclusions need to be interpreted with caution.

In cohort A, 8 patients had core biopsy at three time points; the mean duration of metformin use was 14 days (range 13-18 days) and no patient withdrew. In cohort B, 47 patients had core biopsy at two time points; 17 women completed the metformin course (mean 15.9; range 13-21 days) but a further 7 patients withdrew due to gastrointestinal symptoms including diarrhea, bloating, and/or nausea; $1 / 23$ (4.5\%) not receiving metformin withdrew (no reason given). Symptoms resolved completely after stopping metformin. No patients had a notable change in tumor size on examination during the 23 weeks of metformin therapy.

\section{Ki67}

The mean percentage of cells staining for Ki67 fell after metformin in cohort A by a mean $5 \%(\mathrm{p}=0.041$, paired t-test $)$ and cohort B by a mean $3.4 \%(\mathrm{p}=0.027$, Wilcoxon matched pairs signed rank test), but remained stable in control patients (Table 1; Figure 3).

In pilot cohort A, core biopsies were successfully examined at all three time points (diagnosis, pre-metformin and post-metformin) in 7/8 patients. In the remaining patient there was no cancer in the intermediate, pre-treatment, core. In six patients Ki67 fell significantly with metformin treatment (Figure 3a). The mean percentage of cells stained for Ki67 increased between baseline and interval core samples, from 9.2\% to $10.8 \%$ (not statistically significant). After initiation of the metformin course the mean percentage dropped by $5.1 \%$, from $10.8 \%$ to $5.7 \%$ ( $\mathrm{p}=0.041$, paired t-test). The fall in Ki67 was evident in all but one patient between diagnostic and post-metformin cores, and similarly between interval and post-metformin cores.

In cohort B (Table 1), mean Ki67 and individual Ki67 values fell in all but 2 patients following metformin (Figure 3b) while the mean Ki67 remained stable (but varied for individual control patients between the paired biopsies) in the control group (Figure 3c).

\section{Effects of metformin on serum insulin levels}

Non-fasting paired baseline obtained at the time of diagnosis and, for comparison, preoperative (fasting) insulin levels were successfully obtained in 15/17 of the cohort B metformin patients who completed therapy and in 20/22 of the controls. There was no significant change in serum insulin level in the metformin treated patients (Table 2: $\mathrm{p}=0.663$, two sample t-test; Figure $4 \mathrm{a}$ ) but a statistically significant increase in serum insulin in the control group (Table 2: $\mathrm{p}=0.044$, two sample t-test; Figure $4 \mathrm{~b}$ ). 


\section{Gene array data}

Clinical and pathology data for patients who received metformin and underwent successful array analysis are shown in Table 3 . In cohort A $(n=8)$ there was a loss of patients due to loss due to lack of tumour in one tissue sample (despite guided targeting $)(n=1)$ and failure in the microarray processing $(n=1)$ resulting in cohort A consisting of 6 complete sets of triplicate samples. For the cohort B metformin treated patients $(n=24)$, loss of paired pre treatment and post metformin samples was due to the patient ceasing metformin $(n=7)$ or no tumour/processing failure $(n=3)$ leaving 14 patients with paired microarray data. For the control group in cohort B, only 4 patients underwent paired microarray for financial reasons. Using the differential gene selection and multiple test correction filters, 63 genes for cohort A (p-value < 0.01) and 145 genes for cohort B ( $\mathrm{p}$-value < 0.005$)$ were considered differentially expressed as a result of metformin treatment (supplementary Tables $1 \mathrm{a}$ and $1 \mathrm{~b}$ ). On matching the stringent gene lists ( $\mathrm{p}<0.005$ for inclusion) of cohort A and cohort B, Signal Sequence Receptor gamma (SSR3) was significantly down regulated by metformin in both (Table 4). Using the less stringent gene lists for cohort A ( $n=1360$ genes) and cohort $B(n=1044$ genes), phosphodiesterase 3B, cGMP-inhibited (PDE3B), tumor protein p53 (TP53) transcript variant 5 mRNA and chromosome 16 clone CTD-2542L18 complete sequence (GINS2) were down regulated in both.

\section{Immunohistochemistry validation for PDEB3 and p53}

As for Ki67, core biopsies were successfully examined with PDEB3 (cytoplasmic staining only) and p53 (nuclear staining alone) at all three time points in 7/8 patients (as for Ki67) (Table 5). A fall in PDE3B staining post-metformin was confirmed in 3/7; for p53, little change was observed. These findings are consistent with and support the observations made on the mRNA expression platform.

\section{Ingenuity Pathway Analysis}

Three hundred and ninety-six probe sets were differentially expressed in pre- and postmetformin biopsies ( $\mathrm{p} \leq 0.01)$ (Table 6), 259 over-expressed and 137 under-expressed in the post-metformin biopsy (Supplementary Table 1). We mapped these 396 genes into biological pathways; the most significant top 10 cellular pathways whose members were altered with metformin treatment are shown on Figure 5. The most prominent pathway was Tumour Necrosis Factor Receptor 1 (TNFR1) signaling (Supplementary Figure A-1). The corresponding network figures for metformin regulated pathways (Supplementary Figures A 1-10) illustrate genes over- or under-expressed in the post metformin biopsy (Table 7) and their position in the networks. Eight of the top 10 pathways in the metformin treatment group showed no significant alteration in the control group (Figure $5)$.

\section{Gene Set Analysis (GSA) results}

Ninety-four of the 2987 gene sets examined were affected by metformin treatment ( $\mathrm{p} \leq$ 0.01, Efron-Tibshirani test) including 34 that were over-expressed and 60 that were under-expressed in the post-metformin samples (Supplementary Table 2). To plot the biological network location of these genes we used IPA software, the genes identified 
through GSA as significantly altered by metformin therapy were mapped onto IPA networks (Figure 6; Supplementary Figures B 1-10). 


\section{Discussion}

This two-stage window-of-opportunity trial has highlighted biomarker and clinical effects of metformin in women with early breast cancer. Such preoperative, biopsy-based clinical studies give the opportunity to elucidate the biological effects of drugs on human tumors in vivo, but have the potential caveats, as here, of small patient numbers, insufficient sample material and patient withdrawal due to drug toxicity. Ki67 is a predictive marker for clinical or pathological response in the neoadjuvant setting (reviewed in [20]) suggesting the significant reduction in cell proliferation identified with metformin in this study indicates clinical efficacy. In cohort A we attempted to take into account any effects of core biopsy itself changing Ki67; while there may be differences in Ki67 between sequential samples of the same tumour without any additional intervention, the additional influence of metformin was clear (Figure 3). The wide range of Ki67 values [21] and the ER, PR and HER2 immunohistochemistry in the present study suggest that there was a different mix of luminal A (Ki67<13\% [22]) and luminal B (Ki67>13\% [22]) tumors in the patient groups, possibly contributing to the differences in mean tumour Ki67. The effects of metformin on luminal A \& luminal B tumors have not been examined separately because the trial was not stratified by luminal status and the numbers are small.

Three complementary analytical techniques were used to analyze transcriptome profiling data with subsequent immunohistochemical confirmation of selected genes [23]. This revealed several consistent and biologically plausible observations despite asymmetry in the timing of the metformin (day $0 \mathrm{v}$ day 14) and control (day $0 \mathrm{v}$ day 7 or day $0 \mathrm{v}$ day 14) biopsies, and unequal sample sizes of the various cohorts. Due to the small sample size inherent to window-of-opportunity studies, the results are susceptible to false discovery and apparent differences between baseline and metformin-treated cohorts could also be due to false negative findings; therefore, further independent validation will be required.

The role and regulation of PDE3B (phosphodiesterase 3B, cGMP-inhibited) has been extensively studied in the regulation of glucose and lipid metabolism, in insulin secretion and in adipocyte functions $[24,25,26]$. Although malignant beast epithelium was not micro-dissected free of stroma and thus the combined effect of metformin on both malignant and stromal cells (including adipocytes) was examined, in 3/8 cancers a fall in PDE3B protein expression was confirmed by semi-quantitative immunohistochemistry. This apparent effect of metformin on PDE3B at the mRNA and protein level requires confirmation in larger studies. Down-regulation of PDE3B by metformin in breast cancer could alter the phosphorylation and activation of AMPK with consequent physiological effects. p53 is a key gene which regulates cellular commitment to DNA replication and cell division [27]. Treatment with metformin selectively inhibits growth of p53-deficient colon cancer cells in vivo [28]; while inhibition of breast cancer cell proliferation in vitro may be independent of p53 status [12]. The down regulation of p53 mRNA expression in vivo identified in response to metformin may reflect reduced DNA replication and cell division in primary breast cancers in keeping with the Ki67 data. The signal sequence receptor (SSR), a glycosylated endoplasmic reticulum (ER) membrane receptor associated with protein translocation across the ER membrane [www.ncbi.nlm.nih.gov/refseq], and GINS2 have not been previously linked to breast cancer. 
The exploratory analyses suggesting effects of metformin on key cellular pathways is in keeping with the prominence of transforming growth factor beta (TGFB) up-regulation (identified in the Tumour Necrosis Factor Receptor 1 (TNFR1) signaling pathway) for the inhibition of breast cancer [29] and conversely the failure of the TGFB pathways in the resistance of breast cancer to tamoxifen [30]. This suggests potential synergism between metformin and established breast cancer therapies. Similarly, Cdc42 down regulation, G1/S cell cycle checkpoint regulation, and under expression of p53 signaling appear compatible with the Ki67 data and transcriptome analyses. The mTOR and AMPK pathways also confirmed reduced expression in vitro with metformin $[4,5,10]$, and along with metabolism-related genes over-expressed post-metformin merit future exploration. However, the small numbers of patients and the mixture of breast cancer subtypes require confirmation of the networks and genes highlighted by the ingenuity pathway analysis and gene set analysis in future trials with metformin.

Some known effects of metformin, including activation of AMPK and ACC [10, 11], were not demonstrable in vivo at the mRNA level, reflecting the principle regulation of these proteins by phosphorylation rather than by transcription. It is proposed to examine AMPK phosphorylation and downstream MTOR signaling as a separate sub study in these patients. Other factors may also influence the response to metformin, including the expression of the organic cation transporter 1 (OCT1), which is required for rapid cellular uptake of metformin [5].

The insulin levels were measured non-fasting which, with hindsight, limits the interpretation of the results. Initial blood sampling was at the time of clinical diagnosis and diagnostic/research core biopsy, and thus patients were not fasted. In the case of the pre-operative (second) samples, although taken at surgery and patients had been fasted; patients had intravenous fluids including glucose during anaesthesia. These limitations applied to both groups of patients and the rise in insulin levels seen in the control group could be interpreted as a response to fasting and then a glucose infusion. This change was not seen in the metformin group consistent with the metformin inhibiting gluconeogenesis in response to fasting and hence reducing the insulin response. This study confirms an effect of metformin on circulating insulin levels in non-diabetic patients; however, fasting insulin and glucose measurements at all time points should be considered for future trials of metformin in non-diabetic women since this study is too small to establish safety definitively. The gastrointestinal side effects of metformin were also notable and led to withdrawal of over $20 \%$ of women receiving metformin within this trial. This intolerance may be attributed to the rapid increase in dose required by this study design in order to reach levels expected to affect the breast cancer prior to surgical resection [10]. Future trials using metformin may achieve greater adherence to therapy by increasing metformin exposure more gradually, or by using lower doses of metformin [15].

This trial has demonstrated clear effects of metformin in women with primary breast cancer including the down-regulation of tumour proliferation and down-regulation of PDE3B, a critical regulator of cAMP, which affects the phosphorylation and activation of AMPK. These are all consistent with the effects of metformin seen in breast cancer cell lines [13]. Such biomarkers of metformin effect in vivo may be clinically useful in trials using biguanides in the adjuvant, neoadjuvant and advanced disease settings. 


\section{Acknowledgements}

The authors are particularly grateful to the patients who were willing to give written informed consent in support of this clinical trial and thank the Tayside Multidisciplinary breast team ( Dougal Adamson, Douglas Brown, Emad Elsedawy, Andrew Lee, Denis Mclean, Marta Reis and Valerie Walker) for supporting patient recruitment and facilitating accrual of clinical materials and clinical data to this study.

The trial was conducted through funding from Breast Cancer Research (Scotland), Tenovus Tayside, The Anonymous Trust and Cancer Research-UK.

\section{Declaration of interest}

G Jellema and S Deharo are employees of Almac Dignostics, manufacturer of the Breast Specific Array utlised in the clinical trial for transcriptome analyses. 


\section{References}

1. Evans JM, Donnelly LA, Emslie-Smith AM, Alessi DR, Morris AD. Metformin and reduced risk of cancer in diabetic patients. BMJ 2005; 330(7503): 1304-5.

2. Monami M, Lamanna C, Balzi D, Marchionni N, Mannucci E. Sulphonylureas and cancer: a case-control study. Acta Diabetol 2009; 46(4): 279-84.

3. Jiralerspong S, Palla SL, Giordano SH, Meric-Bernstam F, Liedtke C, Barnett $\mathrm{CM}$, et al. Metformin and pathologic complete responses to neoadjuvant chemotherapy in diabetic patients with breast cancer. J Clin Oncol 2009; 27(20): 3297-302.

4. Zhou G, Myers R, Li Y, Chen Y, Shen X, Fenyk-Melody J, et al. Role of AMPactivated protein kinase in mechanism of metformin action. J Clin Invest 2001; 108(8): 1167-74.

5. Hawley SA, Ross FA, Chevtzoff C, Green KA, Evans A, Fogarty S, et al. Use of cells expressing gamma subunit variants to identify diverse mechanisms of AMPK activation. Cell Metab 2010; 11(6): 554-65.

6. Hardie DG. AMP-activated/SNF1 protein kinases: conserved guardians of cellular energy. Nat Rev Mol Cell Biol 2007; 8(10): 774-85.

7. Kahn BB, Alquier T, Carling D, Hardie DG. AMP-activated protein kinase: ancient energy gauge provides clues to modern understanding of metabolism. Cell Metab 2005; 1(1): 15-25.

8. Salt IP, Johnson G, Ashcroft SJ, Hardie DG. AMP-activated protein kinase is activated by low glucose in cell lines derived from pancreatic beta cells, and may regulate insulin release. Biochem J 1998; 335 ( Pt 3)(Pt 3): 533-9.

9. Marsin AS, Bertrand L, Rider MH, Deprez J, Beauloye C, Vincent MF, et al. Phosphorylation and activation of heart PFK-2 by AMPK has a role in the stimulation of glycolysis during ischaemia. Curr Biol 2000; 10(20): 1247-55. 
10. Zakikhani M, Dowling R, Fantus IG, Sonenberg N, Pollak M. Metformin Is an AMP Kinase-Dependent Growth Inhibitor for Breast Cancer Cells. Cancer Res 2006; 66(21): 10269-73.

11. Hadad SM, Fleming S, Thompson AM. Targeting AMPK: a new therapeutic opportunity in breast cancer. Crit Rev Oncol Hematol 2008; 67(1): 1-7.

12. Zhuang Y, Miskimins WK. Cell cycle arrest in Metformin treated breast cancer cells involves activation of AMPK, downregulation of cyclin D1, and requires p27Kip1 or p21Cip1. J Mol Signal 2008; 3: 18.

13. van der Burg B, Rutteman GR, Blankenstein MA, de Laat SW, van Zoelen EJ. Mitogenic stimulation of human breast cancer cells in a growth factor-defined medium: synergistic action of insulin and estrogen. J Cell Physiol 1988; 134(1): 101-8.

14. Hadad SM, Baker L, Quinlan PR, Robertson KE, Bray SE, Thomson G, et al. Histological evaluation of AMPK signalling in primary breast cancer. BMC Cancer 2009; 9(1): 307.

15. Goodwin PJ, Stambolic V, Lemieux J, Chen BE, Parulekar WR, Gelmon KA, et al. Evaluation of metformin in early breast cancer: a modification of the traditional paradigm for clinical testing of anti-cancer agents. Breast Cancer Res Treat 2011; 126(1): 215-20.

16. Vojtesek B, Bartek J, Midgley CA, Lane DP. An immunochemical analysis of the human nuclear phosphoprotein p53. New monoclonal antibodies and epitope mapping using recombinant p53. J Immunol Methods 1992; 151(1-2): 237-44.

17. Detre S, Saclani Jotti G, Dowsett M. A "quickscore" method for immunohistochemical semiquantitation: validation for oestrogen receptor in breast carcinomas. J Clin Pathol 1995; 48(9): 876-8. 
18. Harvey JM, Clark GM, Osborne CK, Allred DC. Estrogen receptor status by immunohistochemistry is superior to the ligand-binding assay for predicting response to adjuvant endocrine therapy in breast cancer. J Clin Oncol 1999; 17(5): 1474-81.

19. Purdie CA, Jordan LB, McCullough JB, Edwards SL, Cunningham J, Walsh M, et al. HER2 assessment on core biopsy specimens using monoclonal antibody CB11 accurately determines HER2 status in breast carcinoma. Histopathology 2010; 56(6): $702-7$.

20. Yerushalmi R, Woods R, Ravdin PM, Hayes MM, Gelmon KA. Ki67 in breast cancer: prognostic and predictive potential. Lancet Oncol 2010; 11(2): 174-83.

21. de Azambuja E, Cardoso F, de Castro G,Jr, Colozza M, Mano MS, Durbecq V, et al. Ki-67 as prognostic marker in early breast cancer: a meta-analysis of published studies involving 12,155 patients. Br J Cancer 2007; 96(10): 1504-13.

22. Cheang MC, Chia SK, Voduc D, Gao D, Leung S, Snider J, et al. Ki67 index, HER2 status, and prognosis of patients with luminal B breast cancer. J Natl Cancer Inst 2009; 101(10): 736-50.

23. Vendrell JA, Robertson KE, Ravel P, Bray SE, Bajard A, Purdie CA, et al. A candidate molecular signature associated with tamoxifen failure in primary breast cancer. Breast Cancer Res 2008; 10(5): R88.

24. Choi YH, Park S, Hockman S, Zmuda-Trzebiatowska E, Svennelid F, Haluzik M, et al. Alterations in regulation of energy homeostasis in cyclic nucleotide phosphodiesterase 3B-null mice. J Clin Invest 2006; 116(12): 3240-51.

25. Harndahl L, Wierup N, Enerback S, Mulder H, Manganiello VC, Sundler F, et al. Beta-cell-targeted overexpression of phosphodiesterase 3B in mice causes impaired insulin secretion, glucose intolerance, and deranged islet morphology. J Biol Chem 2004; 279(15): 15214-22. 
26. Zmuda-Trzebiatowska E, Oknianska A, Manganiello V, Degerman E. Role of PDE3B in insulin-induced glucose uptake, GLUT-4 translocation and lipogenesis in primary rat adipocytes. Cell Signal 2006; 18(3): 382-90.

27. Vogelstein B, Lane D, Levine AJ. Surfing the p53 network. Nature 2000; 408(6810): 307-10.

28. Buzzai M, Jones RG, Amaravadi RK, Lum JJ, DeBerardinis RJ, Zhao F, et al. Systemic treatment with the antidiabetic drug metformin selectively impairs p53deficient tumor cell growth. Cancer Res 2007; 67(14): 6745-52.

29. Henry LA, Johnson DA, Sarrio D, Lee S, Quinlan PR, Crook T, et al. Endoglin expression in breast tumor cells suppresses invasion and metastasis and correlates with improved clinical outcome. Oncogene 2010; .

30. Lucke CD, Philpott A, Metcalfe JC, Thompson AM, Hughes-Davies L, Kemp PR, et al. Inhibiting mutations in the transforming growth factor beta type 2 receptor in recurrent human breast cancer. Cancer Res 2001; 61(2): 482-5. 


\section{Figure legends}

Figure 1(a): Trial flow diagram. *in 49 patients research cores were not taken at the time of diagnosis, 22 patients declined, 21 patients went to early surgery and in the remaining patients other trials or studies were offered, the study was not offered or no reason was given.

Figure 2: Modified Trial diagram illustrating the source of the samples successfully analysed for transcriptome. * is for metformin treated samples, \# for untreated samples

Figure 3(a) Ki67 expression in cohort A (7 patients): baseline, internal control and following metformin and (b) in cohort $\mathrm{B}$ before and following randomisation to metformin (15 patients) or (c) control group (20 patients)

Figure 4: Individual paired patient data $(n=15)$ of serum insulin levels at baseline and after preoperative metformin (a, left hand panel) and (b) in the control patients

Figure 5. Cellular pathways affected by metformin treatment based on differentially expressed genes

396 significantly differentially expressed genes $(\mathrm{p} \leq 0.01)$ from the metformin treated group and 1,145 genes from the control groups were loaded into Ingenuity Pathway Analysis. The 10 most significant pathways in the metformin group are shown by the black bars. The bars indicate - $\log$ p-values calculated by Fisher's exact test, threshold set at $\mathrm{p}=0.05$. The white bars indicate the significance level of the same pathways in the control, untreated, group.

Figure 6. Biological functions defined by GO categories that were affected by metformin treatment.

All genes that belonged to GO gene sets that were significantly affected by metformin by gene set analysis were loaded to Ingenuity Pathway Analysis. The 20 most significant pathways are shown. The bars indicate -log p-values calculated by Fisher's exact test, threshold set at $\mathrm{p}=0.05$. The line indicates the percent of genes that map to a given pathway from the trial list. Panel A shows the results for the gene sets that were upregulated following metformin treatment and panel B shows the results for the gene sets that were down-regulated by metformin exposure 


\section{Supplementary Figure legends}

Supplementary Figure A. Gene networks revealed by differentially expressed genes using $\underline{\mathrm{t} \text {-test }}$

These figures were generated using Ingenuity Pathway Analysis tool loading the genes that were identified as significantly over or under expressed between baseline and followup biopsies by t-test. $(\mathrm{p} \leq 0.01)$. The top 10 networks are shown, red=genes overexpressed post-metformin and green=under-expressed post-metformin. White= pathway member not present in the gene list of interest.

Supplementary Figure B Gene networks revealed by GSA for metformin effect

These 20 figures were generated using Ingenuity Pathway Analysis loading genes that were significant from the Gene Set Analysis. The genes from Supplementary Table 2 were used and genes were included if parametric $p$ value $\leq 0.1$ (red=genes overexpressed post-metformin, green=under expressed post-metformin, grey $=$ no significant change $(\mathrm{p} \leq$ $0.1)$, white $=$ pathway member not present in the gene list of interest).

Table 1: Baseline and preoperative Ki67. (" paired t-test; ${ }^{*}$ Wilcoxon Matched Pairs Signed Rank Test).

\begin{tabular}{llllllllll}
\hline Group & n. & Ki67 & Mean & $\begin{array}{l}\text { SE } \\
\text { Mean }\end{array}$ & $\begin{array}{l}\text { St } \\
\text { Dev }\end{array}$ & Median & Min & Max & P \\
\hline $\begin{array}{l}\text { Cohort A } \\
\text { Metformin }\end{array}$ & 7 & Baseline & $9.24 \%$ & 2.44 & 6.47 & 7.92 & 2.02 & 21.72 & \\
& 7 & Interval & $10.83 \%$ & 2.34 & 6.20 & 9.84 & 1.39 & 20.79 & \\
& & & & & & & & & \\
Cohort A & 7 & Interval & $10.83 \%$ & 2.34 & 6.20 & 9.84 & 1.39 & 20.79 & \\
Metformin & & & & & & & & & $0.041^{*}$ \\
& 7 & Preoperative & $5.72 \%$ & 2.03 & 5.37 & 4.71 & 0.60 & 15.87 & \\
\hline $\begin{array}{l}\text { Cohort B } \\
\text { Metformin }\end{array}$ & 17 & Baseline & $23.56 \%$ & 3.86 & 15.91 & 16.56 & 8.94 & 59.88 & \\
& 17 & Preoperative & $20.15 \%$ & 3.18 & 13.13 & 16.45 & 6.05 & 45.25 & \\
Cohort B & 22 & Baseline & $14.57 \%$ & 2.43 & 11.38 & 13.16 & 1.31 & 44.76 & \\
Control & 22 & Preoperative & $14.54 \%$ & 3.20 & 15.03 & 10.61 & 0.27 & 51.15 & \\
\hline
\end{tabular}


Table 2: Baseline and preoperative insulin levels (* two sample t-test).

\begin{tabular}{lcllllllll}
\hline Group & n. & Insulin & Mean & $\begin{array}{l}\text { SE } \\
\text { Mean }\end{array}$ & $\begin{array}{l}\text { St } \\
\text { Dev }\end{array}$ & Median & Min & Max & $\mathrm{P}^{*}$ \\
\hline Metformin & 15 & Baseline & 15.73 & 3.77 & 14.71 & 10.00 & 1.00 & 48.00 & 0.663 \\
& & Preop & 16.60 & 3.22 & 12.48 & 15.00 & 1.00 & 42.00 & \\
& & & & & & & & \\
Control & 20 & Baseline & 16.05 & 2.40 & 10.75 & 14.00 & 1.00 & 39.00 & 0.044 \\
& & Preop & 29.80 & 6.01 & 26.88 & 22.50 & 1.00 & 89.00 & \\
\hline
\end{tabular}


Table 3: Combined clinical and pathological (diagnostic core) data of patients who received metformin from whom samples successfully underwent transcriptome analysis.

* Fishers exact test.

\begin{tabular}{lllll}
\hline & & $\begin{array}{l}\text { Cohort A } \\
(\mathrm{n}=6)\end{array}$ & $\begin{array}{l}\text { Cohort B } \\
(\mathrm{n}=14)\end{array}$ & P* \\
\hline Age & $\begin{array}{l}\text { Range (years) } \\
\text { Mean (years) }\end{array}$ & $\begin{array}{l}41-65 \\
52.83\end{array}$ & $\begin{array}{l}44-82 \\
63.35\end{array}$ & N/A \\
Menopausal status & $\begin{array}{l}\text { Pre- and peri- } \\
\text { menopausal }\end{array}$ & $3(50 \%)$ & $2(14.3 \%)$ & 0.131 \\
& $\begin{array}{l}\text { Post-menopausal } \\
\text { Tumour type }\end{array}$ & $3(50 \%)$ & $12(85.7 \%)$ & \\
Histological grade & 1 & $6(100 \%)$ & $12(85.7 \%)$ & 0.478 \\
& 2 & $0(0 \%)$ & $1(7.14 \%)$ & 0.783 \\
$\begin{array}{l}\text { Pathological } \\
\text { tumor size }\end{array}$ & 3 & $3(50 \%)$ & $7(50 \%)$ & \\
$\begin{array}{l}\text { Estrogen receptor } \\
\text { status }\end{array}$ & Pange (mm) & $3(50 \%)$ & $6(42.86 \%)$ & N/A \\
$\begin{array}{l}\text { Progesterone } \\
\text { receptor status }\end{array}$ & Positive & $14-32$ & $9-75$ & 0.521 \\
HER2 status & Positive & 24.16 & 31.28 & $11(78.57 \%)$ \\
& & $6(100 \%)$ & & 0.521 \\
\hline
\end{tabular}


Table 4: Differentially expressed genes by metformin in both cohort A and cohort B.

* Student's t-test.

\begin{tabular}{|lll|ll|}
\hline & & & & \\
\hline $\begin{array}{l}\text { Gene } \\
\text { name }\end{array}$ & Description & Cohort & $\begin{array}{l}\text { Fold } \\
\text { change }\end{array}$ & P* \\
\hline SSR3 & Signal sequence receptor gamma (translocon- & A & -1.60 & 0.009 \\
& associated protein gamma) & B & -1.35 & 0.007 \\
PDE3B & Phosphodiesterase 3B cGMP-inhibited & A & -1.88 & 0.007 \\
& (PDE3B) mRNA. & B & -1.99 & 0.089 \\
TP53 & Tumor protein p53 (TP53) transcript variant 5 & A & -1.79 & 0.062 \\
& mRNA. & B & -3.23 & 0.012 \\
GINS2 & Chromosome 16 clone CTD-2542L18 complete & A & -1.96 & 0.092 \\
& sequence. & B & -4.57 & 0.003 \\
\hline
\end{tabular}


Table 5: Immunohistochemical staining of Ki67, PDE3B, TP53, ER, PR and HER2 in cohort A patients. Reduced expression following metformin indicated by bold figures; increased expression by italics. Scoring of antibody staining as described in the methods.

\begin{tabular}{|c|c|c|c|c|c|c|c|}
\hline Patient & & Ki67 & $\begin{array}{l}\text { PDE3B } \\
\text { (cytoplasm) }\end{array}$ & $\begin{array}{l}\text { TP53 } \\
\text { (nuclear) }\end{array}$ & ER & PR & HER2 \\
\hline \multirow[t]{3}{*}{1} & Diagnostic core & 2.02 & 12 & 4 & 8 & 8 & $2+($ negative $)$ \\
\hline & Premetformin core & 9.84 & 12 & 3 & - & - & - \\
\hline & Postmetformin core & 9.43 & 12 & 2 & - & - & - \\
\hline \multirow[t]{3}{*}{2} & Diagnostic core & 3.62 & 18 & 4 & 8 & 8 & $1+($ negative $)$ \\
\hline & Premetformin core & 8.05 & 12 & 4 & - & - & - \\
\hline & Postmetformin core & 2.17 & 12 & 4 & - & - & - \\
\hline \multirow[t]{3}{*}{3} & Diagnostic core & 7.38 & 12 & 4 & 8 & 8 & 0 (negative) \\
\hline & Premetformin core & 1.39 & 12 & 1 & - & - & - \\
\hline & Postmetformin core & 1.65 & 6 & 2 & - & - & - \\
\hline \multirow[t]{3}{*}{4} & Diagnostic core & 11.24 & 12 & 1 & 8 & 8 & $1+($ negative $)$ \\
\hline & Premetformin core & 15.66 & 12 & 2 & - & - & - \\
\hline & Postmetformin core & 0.60 & 6 & 2 & - & - & - \\
\hline \multirow[t]{3}{*}{5} & Diagnostic core & 21.72 & 5 & 2 & 8 & 3 & $2+$ (negative) \\
\hline & Premetformin core & 20.79 & 5 & 2 & - & - & - \\
\hline & Postmetformin core & 15.87 & 5 & 2 & - & - & - \\
\hline \multirow[t]{3}{*}{6} & Diagnostic core & 22.62 & 18 & 1 & 8 & 3 & $2+$ (negative) \\
\hline & Premetformin core & N/A & N/A & N/A & - & - & - \\
\hline & Postmetformin core & 5.56 & 6 & 1 & - & - & - \\
\hline \multirow[t]{3}{*}{7} & Diagnostic core & 7.92 & 12 & 2 & 8 & 6 & $1+($ negative $)$ \\
\hline & Premetformin core & 12.13 & 12 & 2 & - & - & - \\
\hline & Postmetformin core & 4.71 & 12 & 2 & - & - & - \\
\hline \multirow[t]{3}{*}{8} & Diagnostic core & 10.8 & 18 & 2 & 7 & 8 & 0 (negative) \\
\hline & Premetformin core & 7.94 & 18 & 2 & - & - & - \\
\hline & Postmetformin core & 5.58 & 12 & 2 & - & - & - \\
\hline
\end{tabular}


Table 6. Number of significant genes out of 60,856 probe sets

\begin{tabular}{|c|c|c|c|}
\hline \multirow{2}{*}{ p-value } & Metformin & Controls & \multirow{2}{*}{ Common } \\
\cline { 2 - 3 } & $(\mathbf{n = 2 0})$ & $(\mathbf{n = 9})$ & \\
\hline 0.1 & 5972 & 10519 & 875 \\
\hline 0.05 & 2725 & 5792 & 191 \\
\hline 0.01 & 396 & 1144 & 7 \\
\hline 0.005 & 146 & 554 & 2 \\
\hline
\end{tabular}


Table 7 Key genes up regulated or down regulated appearing in the ingenuity pathway analysis.

\begin{tabular}{|l|l|}
\hline Upregulated & Downregulated \\
\hline TGFB & Cdc42 \\
\hline MEKK & Caspase 2 \\
\hline & \\
\hline Cdk4/6 & PAK1 \\
\hline PP2A & \\
\hline $14-3-3$ & \\
\hline HDAC & \\
\hline
\end{tabular}




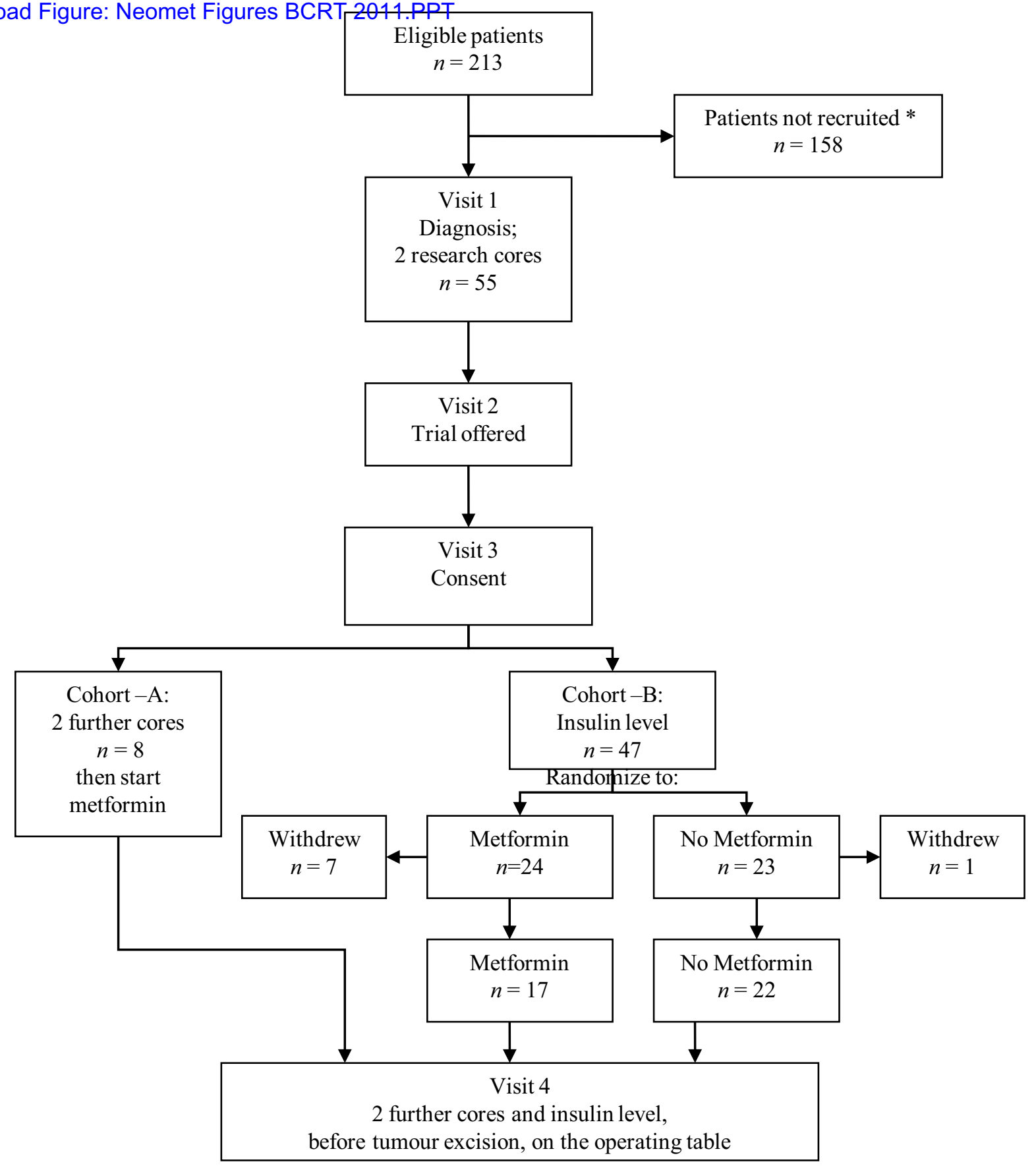


Figure 2

Cohort A

Core biopsy*\#

$n=6$

I week

2 weeks
Core biopsy*

Core biopsy $n=6$ *

$$
n=14
$$

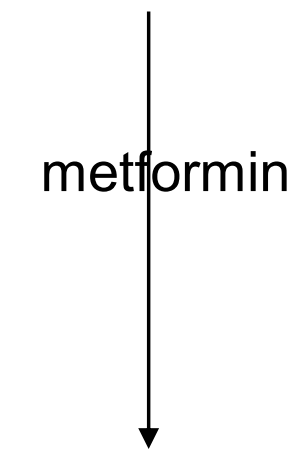

Cohort B

Core biopsy

$n=14^{*}$
Core biopsy\#

$$
n=4
$$

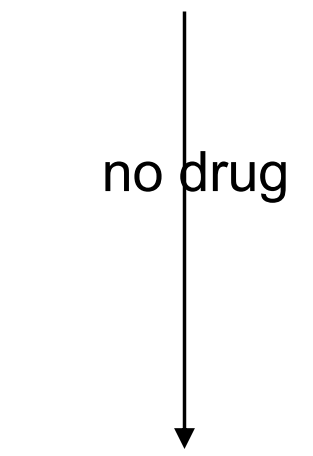

Core biopsy\#

$n=4$ 


\section{Figure 3}
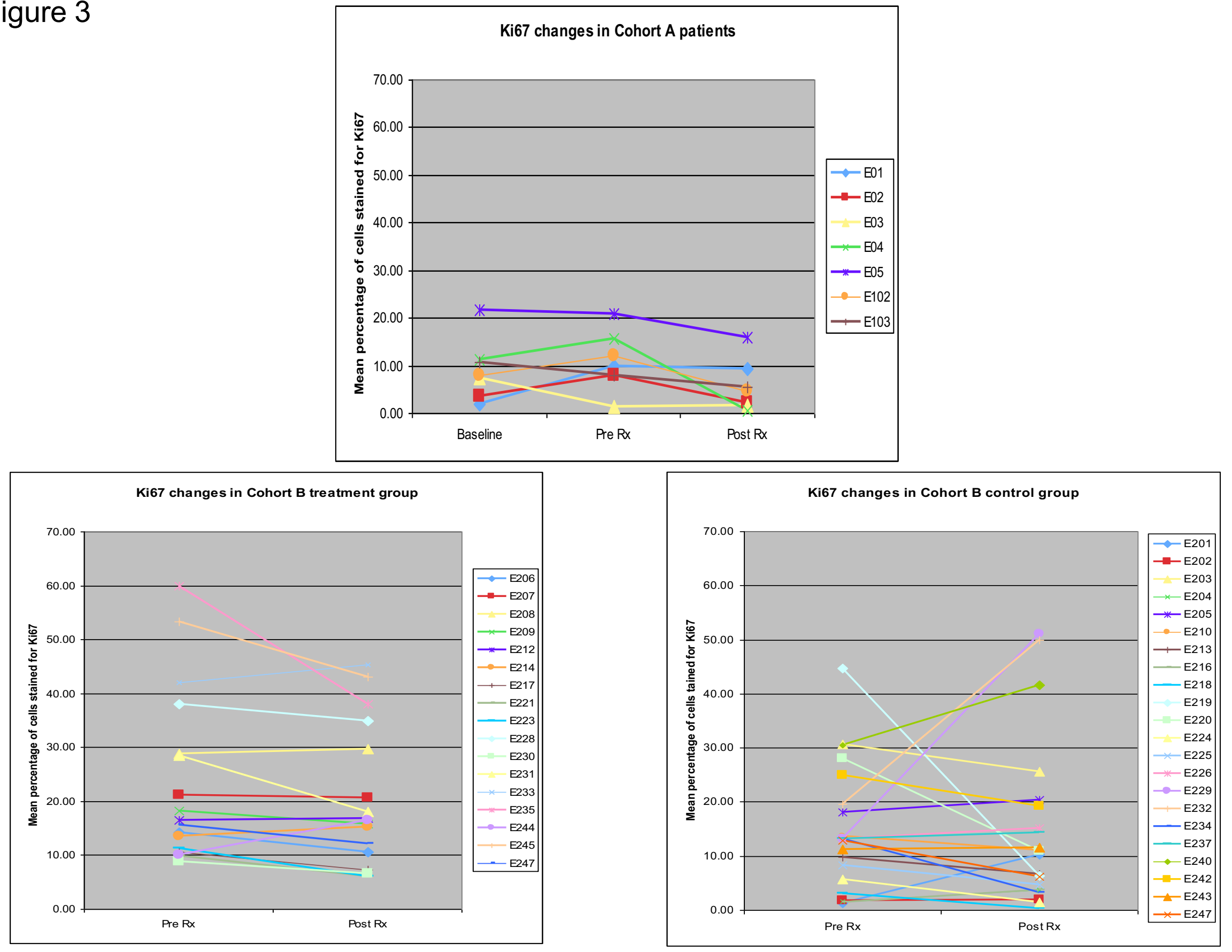


\section{Figure 4}
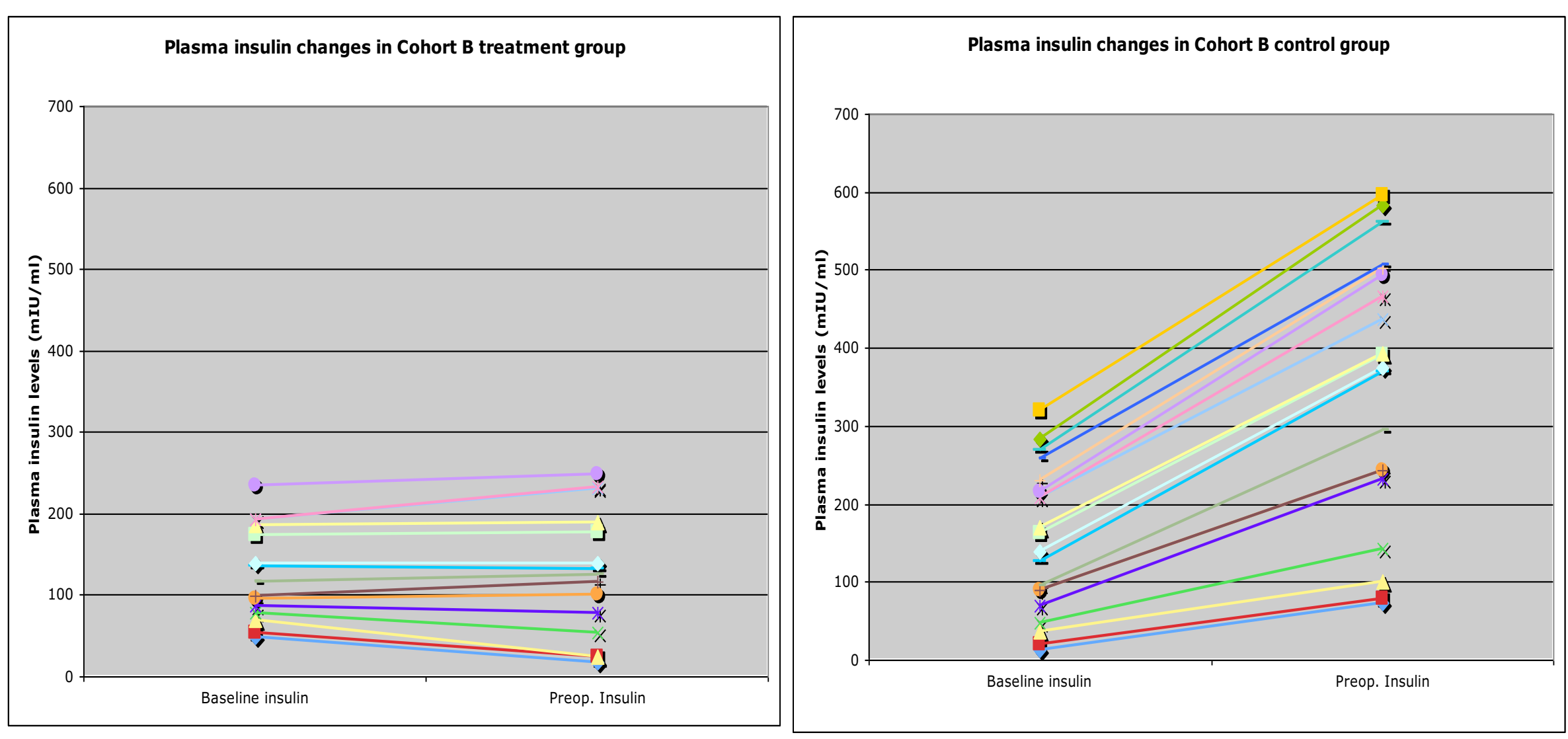


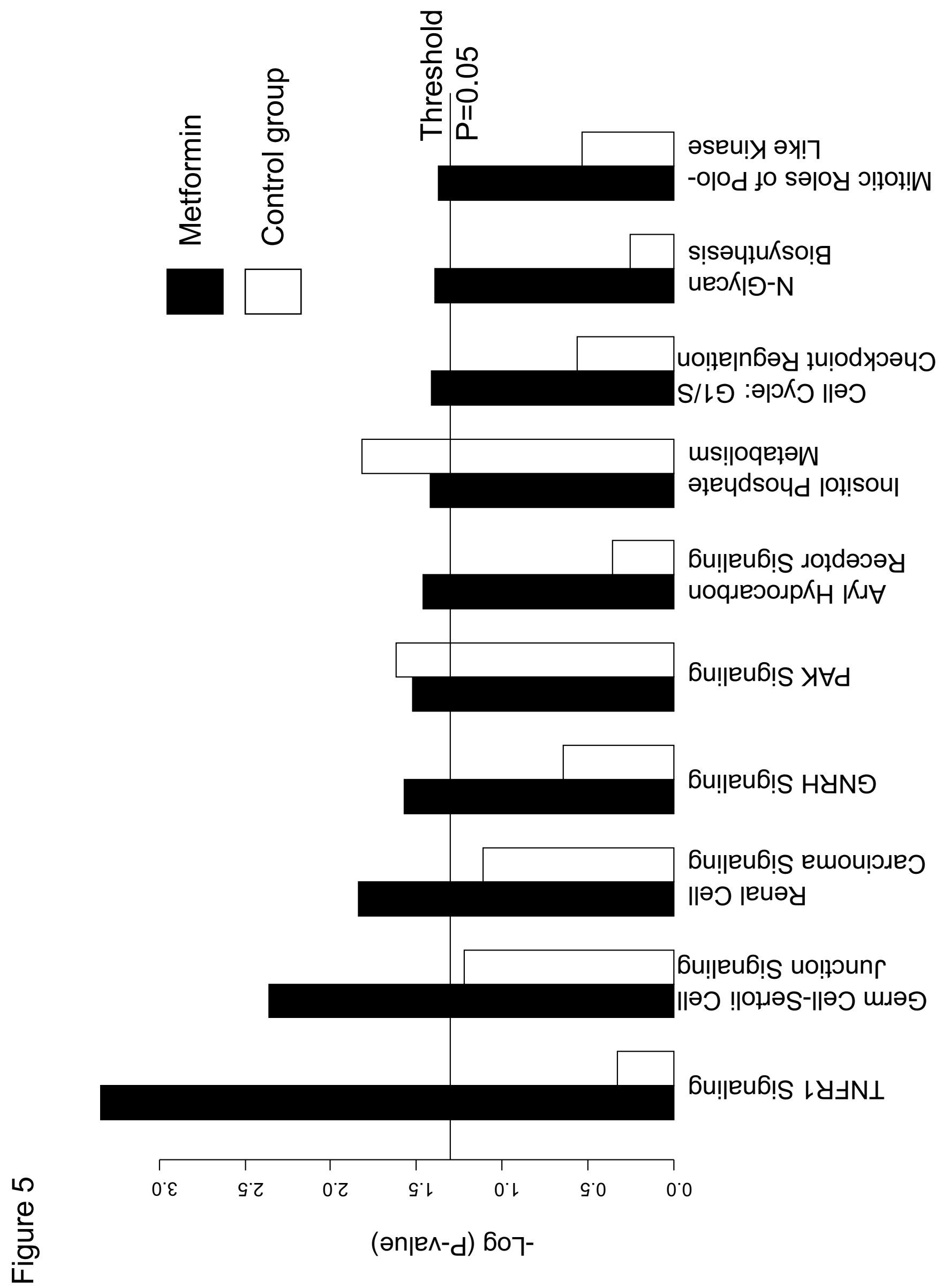




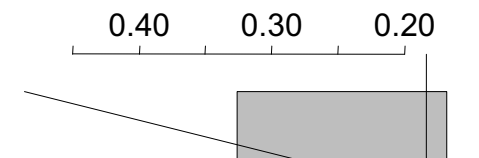

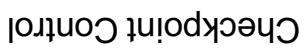

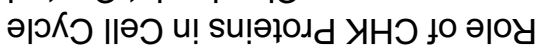

다

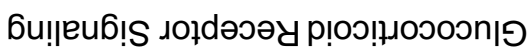

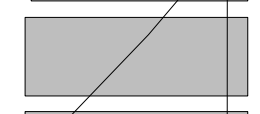

6u!̣eu6!s yoım

6u!!eu6!!s әр!шеләว

6u!|eu6! \& \&sd

əsuodsəy

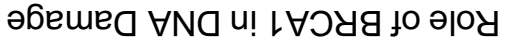

6u!̣eu6!

Би!|eu6! 乙コ一

bu!!eu6!s

YYSS0Ld pue †

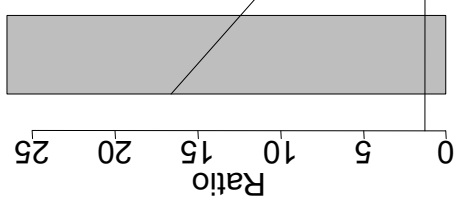

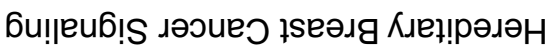

음

$$
\begin{array}{lllll}
0.5 & 0.4 & 0.3 & 0.2 & 0.1
\end{array}
$$

ио!̣e

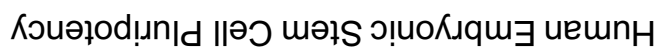

高

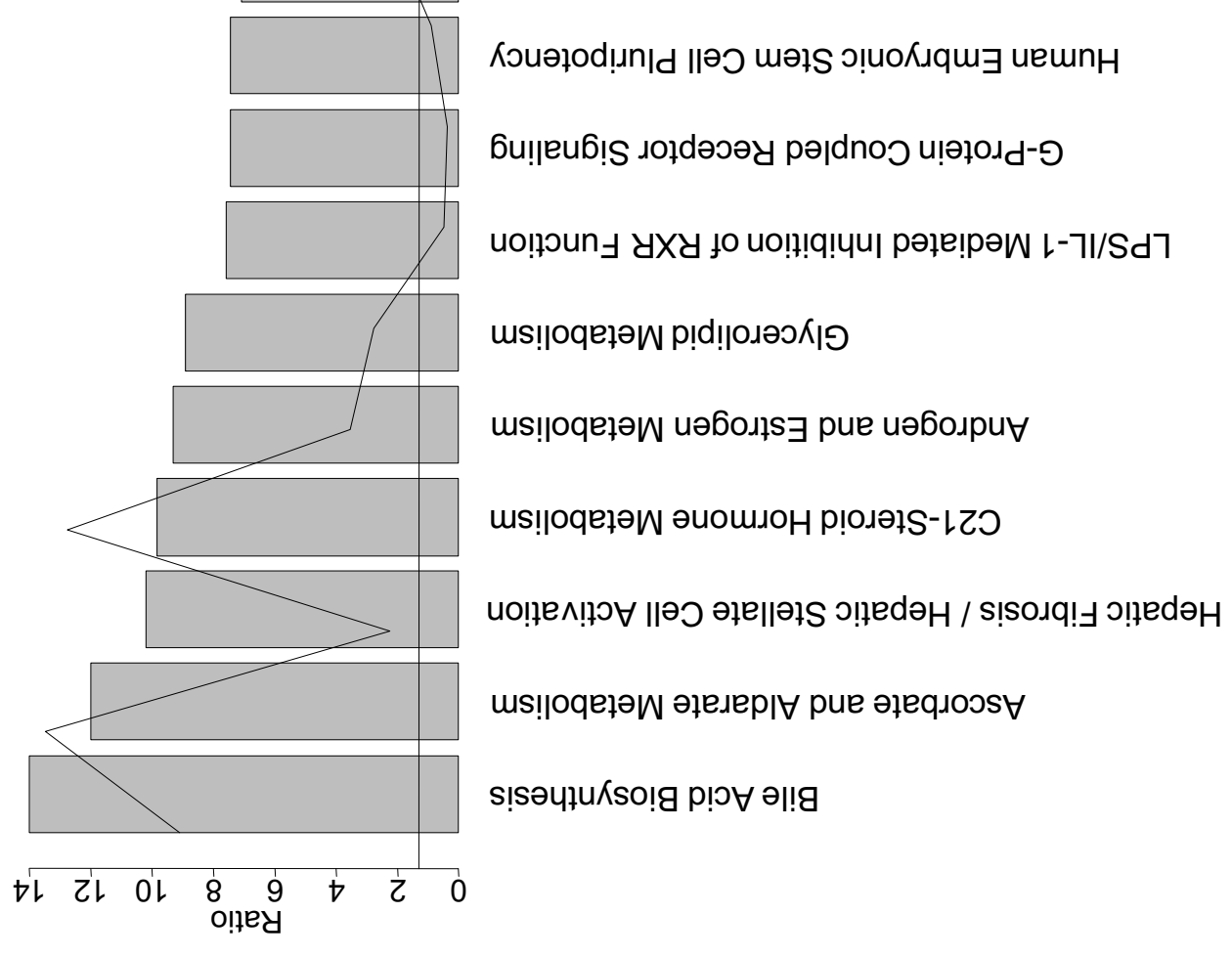

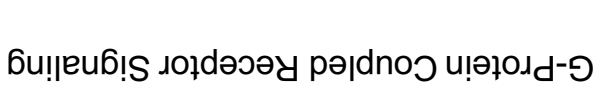

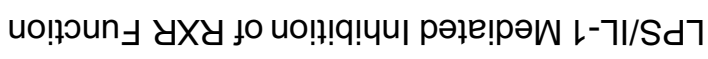

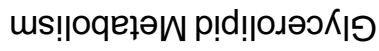

을

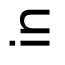

